\title{
El término «Tridimensional» y su contenido ${ }^{1}$
}

Miguel ReALE

40.- Para la sociología jurídica, la ley, la norma, es un reflejo de la vida jurídica concreta. La Ciencia del Derecho sería así, una ciencia de la conducta y no una ciencia de normas. Tenemos ahí, por tanto, dos orientaciones empíricas, ambas pretendiendo partir de la experiencia, pero que llevan a dos soluciones unilaterales. La técnica jurídica se limita a estudiar la regla, con sacrificio del problema del "contenido social», y la sociológica, procediendo de manera inversa, olvida los elementos formales. Ambas corrientes, entre tanto, parten de la experiencia, pero sacrifican la riqueza de la experiencia jurídica, para escoger un ángulo visual, y sobre ese ángulo, apreciar el todo.

I La Teoría Tridimensional del Derecho, de la que es creador el eminente jusfilósofo brasileño Miguel Reale, es ampliamente conocida en nuestro medio, y está presente en las discusiones académicas de hace más de cuarenta años. El maestro paulista puso a punto su tridimensionalismo jurídico en 1953, en la primera edición de su Filosofĭa do Direito. Sin embargo, es un hecho evidente que su concepción no nació del aire, sino fue producto de un largo proceso intelectual, cuyas bases se encuentran en 1940 en su libro Fundamentos do Direito, del cual hay traducción castellana. En este libro, no obstante señalarse la existencia de tres dimensiones en la experiencia jurídica, no se emplea el término "tridimensional», que el autor solo utiliza formalmente y por vez primera en 1953, como ya se ha dicho. Pues bien, en algunas obras, Reale sostiene que el término "tridimensional» y su conceptuación, lo empezó a usar a mediados de la década del cuarenta, lo que me llamó poderosamente la atención. Fue por eso que, sin dudar de la veracidad de este aserto, escribí a Reale pidiéndole me indicase la fuente que acreditase el uso del término "tridimensional» en esa década, ya que yo no había podido obtener constatación alguna. En tal virtud, Reale me remitió una extensa carta confirmando todo ello, y adicionalmente, remitiéndome las partes pertinentes de su curso de Filosofía del Derecho, dictado por él en 1945, en el quinto año de estudios de la Facultad de Derecho de la Universidad de Sao Paulo. Se trata de copias mimeografiadas de la versión taquigráfica de sus lecciones tomada por el hoy Dr. Murilo Antunes Alves, actual vereador 
Si nosotros, por el contrario, demostráramos que la realidad es mucho más compleja de lo que el empirismo pretende, más rica de lo que el positivismo supone, estaremos obligados a intentar superar la posición de estas escuelas, a fin de tomar el Derecho, al mismo tiempo como hecho y como regla, como conducta y como norma; en una síntesis, capaz de darnos la razón de ser de todos los fenómenos jurídicos. Se puede ver, a través de un ejemplo, como esos estudios que parecen tan abstractos, cuando son puestos en contacto con problemas concretos, adquieren expresión de vida y abren camino para soluciones que se manifiestan naturalmente.

Sin anticipar las conclusiones de las próximas clases, podemos decir que el error de la escuela técnico-jurídica, o dogmática, fue el de reducir el Derecho a normas, y considerar el Derecho exclusivamente como una ciencia de normas, y que paralelamente, el error de la escuela sociológica fue considerar al Derecho exclusivamente como ciencia del hecho social. Escapa a ambas orientaciones, la comprensión de que el Derecho es una realidad compleja, no sólo bidimensional (hecho y normal), sino, en realidad, tridimensional: implica un hecho integrado por una norma, en razón de un valor a realizar.

50.- Afirmado el principio de que el Derecho es una realidad, debemos establecer que la realidad, o es dada o es construída. Dada es aqueIla que se ofrece al hombre independiente de su accionar. Por ejemplo, un fenómeno volcánico, el mar o transformación de las minas, operan espontáneamente sin necesidad del hombre, y en algunos casos, en su contra; son fenómenos dados. El hombre los encuentra tal y como son. Al lado de esas realidades dadas, existen las realidades creadas. Son las que resultan de la acción del hombre, de su interferencia al actuar sobre

(concejal) del Concejo Municipal de Sao Paulo. Son copias no autorizadas por la cátedra, en virtud de que éstas representaban un proceso que daría fiutos más adelante, pero que son importantes, pues confirman la aparición del término "tridimensional» en esa época y su configuración unitaria. Así consta en parte de las lecciones 40 y 50 de dicho curso. La carta que me dirigió Reale, ha sido publicada por él («Sobre a origen do termo tridimensionalismo jurídico", en Revista brasileira de Filosofia, fasc. 182, abril - junio de 1996). En esta oportunidad, publicamos esos textos de 1945, que son de gran importancia para comprender la evolución del tridimensionalismo de Reale y que se muestra en una fase muy avanzada de su desarrollo. La traducción al castellano del texto portugués se debe a Mónica Rodríguez Nario; la revisión técnica ha estado a mi cargo (Domingo García Belaunde). 
la naturaleza, teniendo en cuenta la realización de sus fines. Esta realidad se llama cultural, y cuando se transforma a través del tiempo, decimos que es una realidad histórico - cultural.

Veamos cómo ahora estamos en condiciones de concluir que: «El Derecho es un fenómeno histórico-cultural».

¿Cuáles son los elementos que componen esa realidad histórico - cultural? Son tres. Esa realidad es tridimensional. Tenemos ahora la ocasión de mostrar cómo la teoría de los objetos no presenta, absolutamente, separaciones, reservas, grupos que deben ser completamente apartados unos de otros. Por el contrario, nos ofrece una complementariedad esencial. Es lo que se verifica en esa realidad compleja que es el Derecho. El Derecho, antes que nada, es una actitud humana, es una conducta del hombre. Si no existiesen hombres viviendo en comunidad, produciendo cosas útiles, concordando o discutiendo ideas e intereses, no existiría Derecho.

Lo esencial en el Derecho, en primer lugar, es la relacionalidad, o sea, la bilateralidad. El fenómeno jurídico es un fenómeno de conducta social. De entre las múltiples formas de conducta social, distiguimos la conducta social jurídica. El primer elemento, por tanto, es ese de la conducta que llamamos también hecho social: de esta manera, el substractum de toda la vida jurídica, es el hecho social. ¿Pero es ese hecho social indiferenciado? Si decimos que el Derecho tiene un substractum social, ¿no acabaremos disolviendo el Derecho y la Jurisprudencia en Sociología? ¿Entonces, todo es Sociología?

Lo sería si el Derecho fuese apenas un hecho social, la propia conducta social; pero él es un hecho social en cuanto tiende a un valor. No existe derecho donde no existe tentativa de realización de lo justo, o de un valor justo. El hecho social es jurídico, en cuanto tiende a la realización de un valor de lo justo. Pero el estudio del hecho social por la Jurisprudencia no queda ahí, en esa apreciación de la conducta humana en el sentido del valor: La apreciación de un valor a realizar tiene como consecuencia el surgimiento de normas. Toda vez que los hombres procuran realizar un valor, esta búsqueda tiene como resultado el surgimiento de preceptos imperativos de conducta. La conducta se rige por sí misma, a través de los valores a realizar.

De ahí el surgimiento del tercer elemento, que es la norma. Donde quiera que haya una realidad jurídica, encontrarán siempre esos tres elementos: el hecho social integrado por un valor que hace surgir una norma. Existe siempre una realidad jurídica, que se ordena en el sentido de un valor sobre la forma de una norma. La norma es, así, el momento culminante de la vida jurídica. 
El Derecho no es estático, sino dinámico. Es una realidad histórico cultural. El adjetivo «histórico» está allí para mostrar ese sentido dialéctico. El Derecho siempre se está formando, porque los hombres buscan realizar valores nuevos, y cuando los alcanzan, quieren mayores garantías para ellos. Nosotros sólo podemos comprender la evolución histórica del Derecho en su desarrollo, si comprendemos que el Derecho es siempre una conducta humana en busca de valores, a través de normas.

La norma es un medio de realización de garantía de valores, y, al mismo tiempo, un amparo de la conducta social para la comprensión y la solidaridad de todos los que componen la convivencia humana.

Hecho social, valor y norma, son los tres elementos que se complementan recíprocamente. No podemos, a no ser por abstracción, estudiar cada uno de esos elementos, porque en realidad, ellos están unidos. En el momento de la acción, debemos tener en cuenta esa complementariedad.

¿Cuál es el momento de la acción para el jurista? Es, por ejemplo, el momento de la interpretación de una relación jurídica de cara a la ley, para declarar el Derecho.

Es un error interpretar el Derecho pensando que éste es apenas ley o norma, o tan sólo reduciéndolo a valores o a un hecho.

Un juez que sólo vive apegado al texto legal, divorciado de los valores o sin contacto de la realidad social, es un mal juez. Un abogado que, al contrario, se convenza repentinamente de la justicia de una causa y sin consultar la legislación positiva, plantea una acción, es un abogado fracasado. Por otro lado el jurista que sólo quiere ver el hecho social en su entorno histórico, describiéndolo, sin cuidar los problemas del valor y de la norma, es apenas un sociólogo, perdido en el campo de la Jurisprudencia.

El jurista tiene que trabajar con una materia tridimensional, porque sólo esas tres partes unidas nos dan el sentido de la vida del Derecho en su esencia, como la longitud y la profundidad son las que, a la larga, nos dan el volumen de las cosas. El jurista es un hombre que tiene que ver las tres dimensiones, tal como nosotros, en la vida ordinaria, necesitamos de tres dimensiones, o perderemos la ilusión de la perspectiva.

A pesar de la complejidad de la vidad jurídica, existen, entretanto, teorías unilaterales que buscan resaltar un determinado aspecto en detrimento de los otros. Surgen así, tres grandes corrientes al respecto, de las cuales, ya hemos hecho referencia, y que ahora se pueden comprender mejor.

Primero, veamos la corriente que sólo cuida el hecho social, hacien- 
do sociología jurídica. Yo no cuestiono la legitimidad de la sociología para hacer el estudio del Derecho como hecho. Lo que cuestiono es que con tales estudios se puedan procesar las conclusiones que son peculiares al mundo de los valores y de las normas. Yo puedo estudiar cada una de las partes, pero necesito después sintetizar. La investigación es analítica, pero la acción es sintética, y de allí la necesidad de sintetizar el estudio de los tres elementos ya apuntados.

La otra corriente tiene en cuenta tan sólo los valores éticos, preocupándose solamente de aquellos que gobiernan la vida jurídica en el sentido del bien. Dicha corriente se llama eticismo, y cuenta con muchos intérpretes y defensores. Entre ellos, por ejemplo, el jesuíta Cathrein, el cual dice que cuando el juez se encuentra con una ley que sea contra la justicia, debe dejar de aplicar la ley, y si no puede actuar así, debe abandonar su función. Aquí es bueno acentuar que no todos los escolásticos son eticistas. Existen grandes juristas que se inspiran en la doctrina tomista, como George Renard o Delos, quienes aprecian la totalidad del fenómeno jurídico, como lo estamos haciendo, empleando una terminología más actual.

Además de éstas, existe una tercera, el Normativismo, en la cual brilla Hans Kelsen, y que dice que el Derecho es norma. Para dicho jurista, el Derecho solo interesa en cuanto regla, y por tanto, el problema de la Jurisprudencia es un problema técnico y lógico.

Son todas éstas, teorías unilaterales, y por eso debemos tener una visión completa, total, del problema. Decir que el Derecho es un hecho social en cuanto tiende a un valor, es decir que, ontológicamente el Derecho es en cuanto debe ser.

Aquí es preciso abrir un paréntesis para tratar de una materia que es de importancia para nuestras investigaciones. Nosotros decimos que hay dos maneras de apreciar la realidad: según el ser, o según el deber ser. La realidad en sí, por ello, puede ser en cuanto debe ser. El punto de vista lógico de apreciación de la realidad no se confunde con el punto de vista ontológico de estudio de la realidad en sí. El Derecho es una realidad en cuanto debe ser. Lo que caracteriza la realidad jurídica es el hecho de poseer un sentido, un significado, una tendencia para los valores de lo justo. No hay, pues, contradicción en decir que, lógicamente, no hay pasaje del «ser» para el «deber ser»; pero ontológicamente, algo puede «ser» en cuanto «debe ser». 